\title{
De identidades, espacios y miradas. Contribuciones para una fenomenología de la desigualdad social en el espacio urbano*
}

\section{Rafael Hernández Espinosa**}

El presente conjunto de reflexiones aborda el problema de la desigualdad social en los espacios urbanos, especificamente de la Ciudad de México, desde una perspectiva social fenomenológica. Se indaga en las narrativas de sus habitantes las experiencias de desigualdad relativas a interacciones con desconocidos en diversos lugares. Uno de los argumentos resultantes es que las dimensiones espacial, emotiva e identitaria poseen un vínculo fundamental en este tipo de experiencias, a las cuales contribuye el fenómeno de fragmentación social; además el enfoque propuesto es útil para hacer visibles estos vínculos.

Palabras clave: desigualdad social, experiencia, espacio urbano, identidad, Ciudad de México.

Fecha de recepción: 16 de julio de 2013.

Fecha de aceptación: 24 de enero de 2014.

Of Identities, Spaces and Perspectives. Contributions

for a Phenomenology of Social Inequality in Urban Space

This set of reflections addresses the problem of social inequality in urban areas, specifcally in Mexico City, from a phenomenological social perspective. Through the narratives of its inhabitants, it explores the experiences of inequality regarding interactions with strangers in various places. One of the resulting arguments is that spatial, emotional and identity dimensions are closely linked in this type of experience, to which the phenomenon of social fragmentation contributes. The proposed approach is also useful for making these links visible.

Key words: social inequality, experience, urban space, identity, Mexico City.

* Este trabajo forma parte de una investigación doctoral que realizó el autor en el CIESAS, financiada con recursos del Conacyt. Se agradecen las valiosas observaciones de los dictaminadores anónimos.

** Profesor de tiempo parcial en el Departamento de Sociología de la UAM Iztapalapa. Dirección postal: San Rafael Atlixco, núm.186, col. Vicentina, C.P. 09340, México, D.F., México. Correo electrónico:<rafa_he@hotmail.com>. 


\section{Introducción}

Dentro del conjunto de estudios urbanos ha existido un interés predominante por explicar la conformación del orden social desde aspectos macro, y se ha indagado acerca de la función estructural de las instituciones, tanto sociales como culturales, principalmente a partir de datos cuantitativos. Pero, por otro lado, y aunque en menor medida, también se han producido contribuciones importantes desde la escala micro, a partir de enfoques que privilegian la observación de los episodios de la vida cotidiana en la búsqueda de comprender el orden social. El presente trabajo busca contribuir a esta segunda perspectiva al reunir un conjunto de reflexiones en torno a la experiencia de habitar la ciudad en general, y en particular sobre aquellas vivencias de situaciones que ayudan a consolidar la imagen de una sociedad urbana altamente desigual.

La ciudad se vive y se significa en el día a día y en situaciones concretas en las que se interactúa con ella misma y con los habitantes que conforman el conjunto de sus comunidades. Estas experiencias cotidianas, que se nutren de experiencias pasadas y sirven de base para definir situaciones futuras, constituyen el fundamento fenomenológico mediante el cual la ciudad va tomando forma y sentido para la sociedad en general.

En la medida en que nuestro interés es explorar el impacto de las estructuras de desigualdad social en la construcción y el mantenimiento del orden microsocial, es decir, en las situaciones cotidianas cara a cara, es necesario contemplar aquellas dimensiones que proporcionan información relevante en estos ámbitos. Así, la investigación empírica puede centrarse en la narrativa como vía para explorar esos componentes. Tal como se ha venido sosteniendo en la literatura sobre métodos cualitativos, las narraciones permiten a los investigadores acercarse de manera especial a los mundos experienciales de los actores sociales (Taylor y Bogdan, 1994; Flick, 2004), por lo tanto a sus experiencias fenomenológicas de la desigualdad y la exclusión sociales. En esta lógica, los datos empíricos que dan sustento a este trabajo fueron elaborados mediante entrevistas semiestructuradas en torno a tópicos como: a) aspectos ideológicos sobre la exclusión y la desigualdad social, b) percepciones, significados y experiencias en espacios públicos y semipúblicos de la ciudad (el centro comercial, por ejemplo), c) la "presentación de la persona”, y d) interacción y experiencias de desigualdad social. Así, se indagaron los marcos de sentido y los elementos 
identitarios que los actuantes suelen poner en juego en situaciones cotidianas de su andar por la ciudad. Se realizaron 26 entrevistas a hombres y mujeres habitantes de la Zona Metropolitana de la Ciudad de México ${ }^{1}$ tomando en cuenta que residieran allí y que pertenecieran a diferentes niveles y áreas socioeconómicas, principalmente del oriente, sur y poniente de la ciudad, así como que formaran parte de distintas generaciones. Las entrevistas se llevaron a cabo mediante citas previas en diferentes escenarios: algunas en los hogares de los informantes, otras en espacios de encuentro, como los centros comerciales, o en las universidades donde estudian algunos de ellos, entre otros. Se aplicaron entre noviembre de 2008 y diciembre de 2009.

\section{Los marcos de la experiencia}

La perspectiva adoptada en este trabajo parte de explorar la relación entre el desarrollo de ciertas situaciones microsociales y su anclaje en un contexto sociocultural. Dicho anclaje puede observarse desde la dimensión simbólica y subjetiva de las prácticas sociales, y en sus percepciones, significados y experiencias fenomenológicas en general que median entre el nivel estructural y el de las agencias sociales.

Con base en esta lógica se trata de identificar aquellos elementos que vinculan dichos niveles en torno a la experiencia de interacción en un espacio urbano. Un punto importante es conocer, como lo planteó Isaac Joseph (1999), cuáles son los recursos y los repertorios disponibles para un habitante citadino y cómo se dejan ver en un espacio público. La respuesta no es sencilla, pues tales recursos se organizan en formas complejas. Por un lado, se relacionan con saberes pragmáticos ritualizados que regulan el orden microsocial, incluyendo el orden de movilidad en el espacio. Pero por otra parte tales repertorios y recursos se componen también por construcciones sociales de orden simbólico y cultural. Así pues, la pregunta anterior puede plantearse más específicamente de la siguiente manera: ¿cuáles son y cómo se construyen (se producen, se aprenden, se apropian y se reproducen) esos repertorios y recursos que los protagonistas del espacio urbano ponen en juego?

${ }^{1}$ En la medida en que el proyecto de investigación se concentró en la construcción del orden social y la desigualdad en los centros comerciales de la Ciudad de México, se incluyó en las entrevistas a 13 empleados de tres centros comerciales (Centro Santa Fe, Parque Delta y Plaza del Salado). 
En Frame Analisys, Goffman (2006) enfatizó la existencia de lo que llamó marcos de referencia para describir a aquellos elementos básicos que permitirían comprender cómo se entrelazan los principios de organización que gobiernan los acontecimientos sociales y nuestra participación subjetiva en ellos. ${ }^{2}$ Los marcos serían una especie de esquemas interpretativos que permitirían a los actuantes en una determinada escena social elaborar una definición común de la realidad y en este sentido aplicar conjeturas sobre lo ocurrido previamente, así como anticipar expectativas sobre lo que probablemente ocurrirá después. Por lo tanto, son marcos de referencia que constituyen un elemento central de la cultura de un grupo social.

En otro momento Harvey Sacks (2000) se aproximó de un modo similar a la cuestión de la definición de las situaciones reflexionando sobre la manera en que las personas construyen sus inferencias sobre los hechos sociales. El autor se preguntó cómo funcionaría una máquina de hacer inferencias y planteó como parte de la respuesta la necesaria existencia de un conjunto de normas, así como la de un conjunto de objetos manejados por esas normas. La información que esa "máquina" maneja para la construcción de inferencias se da en una especie de colecciones de categorías interpretativas. En términos sociales, esas colecciones de categorías de normas y de objetos se hallan en el seno de la vida social y son aprehendidas mediante la socialización.

Estas dos propuestas se encuentran vinculadas con la herencia sociofenomenológica de Alfred Schütz, específicamente en el interés por la constitución de lo que llamó el "repositorio de conocimiento disponible" (Schütz, 1993 y 2003). Para dicho autor el mundo del sentido común se encuentra tipificado en categorías de significado que permiten reconocer los fenómenos e incorporarlos a la conciencia del sujeto mediante el repositorio de conocimientos disponible. Este repositorio se conforma mediante las experiencias biográficas que participan en la intersubjetividad de un grupo social. En este sentido, lo que se recupera como marco epistemológico en esta investigación es el énfasis en dicho proceso de tipificación, así como en la conformación del catálogo intersubjetivo de estas tipificaciones o categorías del sentido común.

2 Goffman los define específicamente como marcos primarios y los divide en dos tipos: naturales y sociales. Los primeros se refieren a la explicación de acontecimientos no guiados o debidos a determinantes naturales. Los segundos se refieren a los entendimientos de acontecimientos que incorporan la participación de una agencia viva, es decir a los "haceres guiados" (2006: 23-24). 
En un sentido parecido puede ser pertinente la noción de "hábitus" que desarrolla Pierre Bourdieu, el cual se refiere al conjunto de sistemas de clasificación, de esquemas mentales y corporales, que funge como matriz simbólica de las actividades prácticas, las conductas, los sentimientos, los pensamientos y los juicios de los agentes sociales (Waquant, 1995). Es en este sentido que el hábitus puede ser entendido como una subjetividad socializada (Bourdieu, 1995), en la cual pueden enmarcarse un conjunto de prácticas significantes. Es decir, estas subjetividades socializadas aparecen como una especie de colecciones de categorías, en términos de Sacks o de Goffman. ${ }^{3}$

En resumen, podemos afirmar que estos componentes de la dimensión simbólico-subjetiva son básicos para la comprensión y explicación del sentido de los acontecimientos, tanto para los actores como para el científico. La vida cotidiana de los actores sociales transcurre no sólo dentro de estructuras espaciales y materiales en las ciudades, sino también en torno de estructuras socioculturales, que implican normas e instituciones formales e informales. Una de las estructuras de mayor implicación para la mayoría de las sociedades es la estratificación social. Ésta, dice Weber (1974), está imbricada en los elementos políticos, económicos y sociales, de los cuales el tercero posee un aspecto netamente simbólico: el honor o estatus, que es una fuente esencial de la diferenciación social. Así, tal como sostienen Berger y Luckman (1988), la construcción social de la realidad implica la internalización de las estructuras e instituciones sociales mediante procesos de tipificación; en este caso la estratificación implica también la objetivación de la realidad subjetiva y simbólica mediante las acciones que en nuestro ejemplo son las prácticas de diferenciación social.

Con base en lo anterior, en los siguientes apartados se identifican algunos de estos marcos que forman parte de la experiencia de la ciudad y que intervienen en los procesos de diferenciación social. En otras palabras, se busca explorar un aspecto de la eficacia simbólica de la estructura social, principalmente el relativo a la desigualdad y a la estratificación, en la experiencia del espacio urbano.

\footnotetext{
3 Bourdieu, por otro lado, mantuvo la preocupación por los riesgos de desvincular del problema las constricciones estructurales hacia el comportamiento. Esta perspectiva nos recuerda entonces que en un problema de investigación siempre se tendría que considerar lo que podemos llamar un diálogo de eficacias simbólicas y estructurales en el seno mismo de la acción y la interacción social.
} 


\section{Significados de la desigualdad y de la estratificación social}

Para acercarnos a una deconstrucción de la experiencia urbana de la desigualdad es pertinente revisar brevemente los significados que se asocian a tal desigualdad y a la estratificación social e ir incorporando paulatinamente vínculos con la experiencia de la ciudad. La caracterización del nivel socioeconómico de los informantes está basada en el Índice de Nivel Socioeconómico que realiza la Asociación Mexicana de Agencias de Investigación de Mercados y Opinión Pública (AMAI), cuya estructura jerárquica incluye la acumulación de capital económico y social (López Romo, 2008). En dicho índice se establecen los niveles $\mathrm{A} / \mathrm{B}, \mathrm{C}+, \mathrm{C}, \mathrm{D}+, \mathrm{D}$ y E, que en una nomenclatura de clases o estratos corresponden a las clases alta $(\mathrm{A} / \mathrm{B})$, media alta $(\mathrm{C}+)$, media (C), media baja (D+) y baja (D y E). En la presente caracterización se toman en cuenta principalmente el tipo de actividad económica de los jefes de familia, el lugar de residencia, las trayectorias laborales, los tipos de empleo y los niveles y tipos de instrucción escolar. Estos tipos de datos permiten reflexionar no sólo en términos de ingresos, sino también en cuanto a los capitales sociales y culturales, que representan "la aptitud de los actores para asegurarse beneficios en virtud de la pertenencia a redes u otras estructuras sociales" (Portes, 1999: 248), de tal suerte que algunos testimonios de este apartado estarán enmarcados dentro de dicho modelo de estratificación social.

Cabe mencionar como primer punto que todos los informantes reconocieron la existencia de la desigualdad; sin embargo es interesante que el grado de dicha desigualdad no parece ser similar para todos, ni en los mismos términos. Ello está asociado con ciertos patrones de las experiencias biográficas en que aparecen algunos elementos determinantes, como la zona de residencia, la trayectoria laboral y escolar, los grupos de pertenencia, la edad, el género y la condición socioeconómica en general. Es decir, dichos elementos influyen significativamente en la forma de definir la realidad social, así como en la constitución de las identidades y la definición de las situaciones de interacción en las que se participa.

Algunos informantes, tanto jóvenes como adultos, declararon inicialmente que creen en la existencia de una condición de igualdad generalizada que a todos nos adscribe en la categoría de seres humanos, o "personas". No obstante, también aparecieron razonamientos menos generales como los alusivos al género, principalmente entre las mujeres. Algunas de ellas, por ejemplo, reconocieron que si bien existe la desi- 
gualdad, ahora es menor que antes. Por otra parte, al llevar la conversación hacia aspectos más mundanos y materiales, estrictamente socioeconómicos, la respuesta de los informantes es rotunda en el sentido de que existe una clara diferenciación en la sociedad de la que forman parte.

Sin embargo la percepción social de esta diferenciación es complicada y posee diversos matices importantes para el análisis. Resultan interesantes las percepciones de la estratificación social, así como la identificación propia con uno de estos estratos. Este conjunto de percepciones es fundamental para aproximarnos a comprender la experiencia de la desigualdad en la ciudad.

De acuerdo con los testimonios de nuestros informantes, la noción general de la estratificación, independientemente de la posición que se ocupe en ella, está formada por una clasificación en las tres categorías clásicas: clase alta, clase media y clase baja. Muy probablemente se trata de una reproducción del discurso escolar. Sin embargo, en un examen más minucioso, buena parte de los testimonios de los entrevistados se refiere a una categoría adicional en el extremo inferior de este modelo de estratificación, que consiste en lo que llamaron la clase "extra pobre", "los muy pobres" o "en extrema pobreza", en alusión a una condición social que, para ellos, no existía antes. También son interesantes al respecto algunas referencias en el sentido de que la clase media "ya no existe" o "está desapareciendo", específicamente en informantes que oficialmente calificaríamos como de estratos medio o medio-bajo.

Si aunamos esta última opinión a la de quienes añaden la categoría de extrema pobreza, ambas ancladas en una perspectiva temporal, el imaginario resultante es el de una agudización de la polarización socioeconómica. Ésta, además del componente económico, también se vincula con el trasfondo del conflicto político nacional y con la agitada atmósfera social que la ciudad ha venido presenciando en los últimos años, ${ }^{4}$ en la cual se exacerba la confrontación de ideologías traslapada con el conflicto de clases.

Resulta interesante lo que conforme a tales percepciones marca las diferencias entre las clases; son percepciones que a su vez sirven como contexto para enmarcar la autoadscripción como parte de la identidad social. Encontramos que algunos de los elementos significativos para definir una u otra clase social están determinados por las

${ }^{4}$ Claro está, sin negar también el papel que han tenido en ello los medios masivos de comunicación audiovisual. 
experiencias del entrevistado en su entorno próximo o cotidiano. En general dichas percepciones aparecen permeadas por los discursos sociales que tipifican a los pobres y a los ricos a partir de posesiones materiales y de prácticas socioculturales que los definen y clasifican en estilos de vida diferenciados. Sin embargo resulta interesante que al comparar las visiones entre diferentes sectores sobre la diferenciación de clases se enfaticen elementos diversos. Así, al considerar los aspectos definitorios de la clase privilegiada, por ejemplo, los estratos bajos no consideran como aspecto principal el hecho de poseer servidumbre, como lo hacen los estratos más favorecidos. Por otro lado, éstos tampoco destacan el que tengan o no coche y puedan acceder o no a diversas tecnologías, sino el tipo y la calidad de éstas.

Esta relatividad de percepciones refleja un efecto de la fragmentación social y socioespacial en la ciudad, en el sentido en que la realidad de un grupo social se define a partir de los elementos que le resultan más cotidianos y con los cuales se tiene más cercanía y familiaridad. Dicha relatividad de percepciones está presente también en los procesos de autopercepción respecto a la escala socioeconómica. Como mencionamos, nos interesa particularmente el proceso de autocategorización o posicionamiento subjetivo que los propios sujetos hacen de sí mismos en sus propios mapas sociales, pues ello es extremadamente importante al definir la situación y al actuar en consecuencia.

En los testimonios se observa que aunque la gran mayoría de los entrevistados se autoadscribe a la clase media, aspecto por demás interesante, esta clase no parece ser la misma para todos. Una de las informantes jóvenes, por ejemplo, en sus relatos iniciales utiliza la frase: "entre los pobres nos ayudamos" que implica una autocategorización de estrato bajo; posteriormente, al preguntarle sobre el sector social con el que se identifica, se adscribe a la clase media, señalando que no pertenece al grupo de los ricos, pero que existe también gente muy pobre. Es importante observar que en este tipo de testimonios, como el de otro joven de estrato bajo, los ricos parecen ser el conjunto de la sociedad que las estadísticas oficiales incluyen en las clases medias y altas, sin mayores diferencias. Por otro lado, encontramos informantes provenientes del sector medio-alto que se asumen también como clase media, a partir de que no se consideran "en el exceso" ni en la carencia y ponen énfasis en los elementos extremadamente lujosos con los que no cuentan.

Parece claro entonces que la relatividad de percepciones de clase está influenciada por la relatividad de sus propias experiencias de 
clase. Según estudios sobre la segregación espacial urbana, ésta tiende a generar distanciamiento y aislamiento social entre grupos que coexisten pero no interactúan (Saraví, 2004 y 2008). Dicho aislamiento social permite entonces la diferenciación de ciertas pautas culturales (formas de hablar, de vestir, gustos, tipos de consumo, etc.) así como percepciones particulares de la realidad social (la política, la economía, la inseguridad, la desigualdad, los derechos, etc.) entre distintos grupos (Hernández Espinosa, 2009). De esta manera tanto la existencia de percepciones diferenciadas de la estratificación desde distintos estratos, así como la tendencia a percibirse dentro de un nivel socioeconómico medio (aun de quienes oficialmente no serían situados ahí), parecen contribuir a la fragmentación y al aislamiento social que propicia la segregación espacial o división social del espacio.

Pero, ¿qué más podemos decir acerca de la tendencia a situarse en un punto intermedio? En nuestra opinión es necesario indagar en el proceso por el cual una persona "elige" intencionalmente dar una presentación específica de sí, es decir lo que Goffman analizó con el concepto de presentación de la persona. Una interpretación superficial podría ser que existe un imaginario de una "amplia" clase media de la cual la mayoría formamos parte. Sin embargo, como vimos líneas arriba, algunas percepciones reconocen la emergencia de un sector en extrema pobreza y además observan cierta disminución o desaparición de la misma clase media. ${ }^{5}$ En efecto, las opiniones de este tipo contradicen un poco aquella idea, pues hacen parecer a la clase media como una especie de ficción y a la vez sugieren que la sociedad puede verse dividida entre ricos y pobres: la gente "como yo" y "los otros". De tal manera, el recurso de autoadscribirse a un estrato social medio, aunque en el fondo parezca una ficción, es también una forma de posicionarse virtualmente en una "zona neutral" desde la cual se parte para evadir una posible hostilidad, dado el latente distanciamiento de clase. Esta explicación alude a un componente pragmático y resulta importante para el análisis de las interacciones.

Es importante observar que ambas explicaciones, la de una autopercepción "ingenua" y una presentación intencional, no necesariamente son contradictorias, sino que suelen ser adoptadas dependiendo de la fase de reflexividad de las personas. Los ejemplos más representativos aparecen entre los estratos sociales medio y bajo, que suelen

${ }^{5}$ Lo interesante en este punto es que aun cuando la mayoría de las personas se define como de clase media, ésta suele ser diferente para cada sector, principalmente cuando hay escasa sociabilidad entre los mismos. 
tener experiencias de sociabilidad o de simple contacto con ámbitos de estratos sociales diferentes en el trabajo o en la escuela, por ejemplo en la universidad (Hernández Espinosa, 2009).${ }^{6}$ Un ejemplo de lo dicho es el caso de un joven que describe cómo se ha transformado su percepción en torno a su posición social a partir de experiencias que lo han llevado a desarrollar mayor reflexividad sobre su posición de clase:

Yo, según, decía que era [clase] media, pero creo que no. Soy pobre porque ni siquiera automóvil tengo. Y digamos que los de clase media tal vez tienen un automóvil, ya viejito o bueno, no sé, sino un auto más o menos. Entonces, el que tiene un automóvil es un gasto más, una obligación más. Entonces yo creo que soy de la clase pobre, no tengo automóvil, no tengo, en mi casa..., ni siquiera tengo casa, la casa es de mi papá. Entonces... no tengo nada, si acaso mi ropa.

[Entrevistador: Pero, ¿cómo está eso?, decías que eras de clase media y después ya no.]

Creo que fue analizando lo que nosotros teníamos ¿no? Por ejemplo, no tengo Sky, no tengo Cablevisión, es otro gasto más. Y entonces cada vez que hacía comparaciones, digamos entre tres personas, digamos de diferentes estatus, te das cuenta de que no tengo eso, no tengo eso, no tengo eso; y él tiene esto, y esto, pero le falta eso; él no tiene eso, entonces tú dices ¡ah... ya! Entonces las personas también, nos damos cuenta porque cada uno carece de cosas y así. Entonces la clase alta es la que tiene casi todo, casi todo [Javier, 24 años, estudiante de licenciatura, habitante de Santa Marta, Iztapalapa].

En concreto, este problema suscita la reflexión en torno a una dimensión subjetiva de la estratificación social y de la propia posición social frente a la estratificación definida "objetivamente" por las versiones oficiales. Esta reflexión nos permite en primer lugar observar cómo la realidad que construyen los grupos sociales se ve permeada (sin embargo no determinada) por las condiciones materiales que les impone su posición en la estructura social. Podemos sostener que las clasificaciones o tipificaciones asignadas a un grupo social o persona

${ }^{6}$ Es posible que en ocasiones una entrevista contribuya a transformar las percepciones de la realidad porque el entrevistado se ve obligado a reflexionar y a formular argumentos en el momento. No obstante resulta interesante la misma creencia y autopresentación de pertenencia a una clase media que parece constituir una ficción cuando se reflexiona más profundamente. 
"desde afuera" no siempre son ratificadas por los mismos sujetos. El distanciamiento social puede favorecer en algunos sectores una percepción muy relativa respecto a ciertos elementos de la realidad, como la estratificación, lo que implica un posicionamiento en ésta. Sin embargo algunas experiencias biográficas en diferentes contextos culturales y socioespaciales posibilitan el acceso a un horizonte más amplio de conocimientos, y con ello cuestionar las propias percepciones de la realidad.

No obstante, el tener un panorama más amplio del mapa social no descarta la posibilidad de presentarse a sí mismo en una posición neutral, pues en nuestra opinión constituye un acto práctico que permite solventar la dinámica de confrontación social establecida en las estructuras de desigualdad social. Si aceptamos la idea de que la identidad suele ser versátil y dinámica, es decir, que no es fija y que su configuración depende, entre otras cosas, también de elementos pragmáticos, situacionales y relacionales, podemos plantear que el posicionamiento de clase en términos virtuales, discursivos, constituye un recurso importante de presentación de la persona.

\section{La ciudad, el espacio y la desigualdad}

Un elemento que permite ir delimitando el problema en torno a la experiencia de la Ciudad de México es precisamente el uso y significación de sus diversos espacios. Una cuestión central para este trabajo se relaciona con la diferenciación social entre áreas específicas de la ciudad, es decir, la división social del espacio. No obstante, más allá del debate académico en torno a este fenómeno (véase Machado Barbosa, 2001; Caldeira, 2007; Duhau, 2003; Saraví, 2004; Schteingart, 2008), nos interesa abordarlo ahora desde lo que podría llamarse una geografía ingenua o geografía subjetiva. Es decir, abordar la manera en que los actores sociales usuarios de la ciudad la perciben y construyen socialmente a partir de sus experiencias, directas e indirectas, en torno a su división socioespacial. En este sentido, el presente apartado presenta un análisis de la experiencia fenomenológica de la ciudad en tanto ciudad diferenciada social y espacialmente; asimismo se destacan los efectos subjetivos de la desigualdad social en dichas experiencias.

Como ha reconocido la geografía, el ser humano no se comporta en el espacio citadino racionalmente (en términos de racionalidad económica), sino que lo hace en función de la imagen subjetiva que 
posee de la ciudad (Somoza Medina, 1995). Los sujetos poseen una imagen parcial del espacio urbano en función de la cual actúan y deciden su comportamiento. Más allá de una ciudad objetiva está la que se utiliza, apropiada por las imágenes que la gente se forja. El comportamiento depende en parte de esos imaginarios. Reaccionamos frente al entorno que percibimos, y nuestra actitud resulta más condicionada por nuestra experiencia subjetiva que por las condiciones "objetivas" del espacio. El espacio entonces no puede ser interpretado como un campo neutro donde se desarrollan funciones y procesos, sino como un escenario vivido en el que se forjan situaciones, significados, imágenes, sentidos y afectos. Además, el espacio caracterizado como neutral y separado de la estructura social esconde el hecho de que es político e ideológico (Sznol, 2007).

Con relación a la información obtenida en las entrevistas, las referencias en torno a la percepción espacial de la ciudad incluyen algunos tópicos de diferenciación y segmentación de ésta, y uno de los más representativos es el de la dimensión socioeconómica. A la percepción de dichas diferencias socioeconómicas entre "zonas" contribuyen principalmente ciertas tipificaciones que incluyen el "tipo de gente" que reside, el equipamiento urbano, el desarrollo comercial y la calidad de la imagen urbana. No obstante, es principalmente en el ámbito de la residencia, es decir, en el tipo de viviendas, el tipo de fraccionamiento y el tipo de residentes, en su conjunto, donde se definen las diferencias sociales del espacio urbano para los residentes. En general son representativas de zonas "bien”, de nivel socioeconómico alto, Polanco, Las Lomas, Santa Fe y El Pedregal, entre otras, todas ellas ubicadas en la parte poniente de la ciudad en una franja norponiente-sur. Resulta interesante que para los sectores populares que habitan en las zonas periféricas del oriente, las zonas de mayor bienestar se extiendan hacia algunas colonias de las delegaciones Coyoacán, Benito Juárez y Cuauhtémoc, las cuales se asocian a un imaginario del "centro".

En este caso podemos observar que la percepción espacial en torno a la división social también está influida por el efecto de la segregación espacial, pues los sectores populares de la periferia asocian casi el resto de la ciudad, que normalmente no transitan, con un sector social más favorecido, es decir, el de "los ricos". Como expusimos anteriormente, la dimensión residencial suele ser uno de los principales factores definitorios de la percepción de diferencias socioespaciales. Por ejemplo, las zonas asociadas con el nivel socioeconómico alto se suelen relacionar con la residencia de los "artistas", es decir, actores 
de cine y de televisión y los cantantes famosos, así como con los grandes empresarios y políticos de élite. Incluso los mismos residentes también sostienen una percepción similar en el sentido de que suelen ser zonas prestigiadas.

Por otra parte, las zonas de la metrópoli asociadas a las clases populares, digamos baja y media baja, son en general las de la región oriente, es decir, de la delegación Iztapalapa y los municipios de Nezahualcóyotl y Ecatepec, por no mencionar las áreas deterioradas del centro y entidades más periféricas. A esta amplia región se le atribuye una fama negativa, pues pesa sobre ella un estigma generalizado que se asocia con la inseguridad, la violencia, la delincuencia, el analfabetismo, la pobreza, etc., que también se extiende a los mismos residentes de la zona. Resulta interesante advertir que los mismos residentes suelen ser conscientes de dichos estigmas y en función de ello retroalimentan su percepción en torno a las diferencias socioespaciales. Como menciona la socióloga Eva Machado Barbosa (2001), los principales determinantes de la segregación vienen dados por los niveles societal (estructural) y físico-espacial, además del simbólico. Éste se refiere tanto a los patrones culturales como a los elementos psicológicos que afectan al proceso de la segregación espacial a través de la percepción de la identidad individual y colectiva.

De esta manera, dichos imaginarios colectivos contribuyen a la construcción de mapas sociales que involucran no sólo la cuestión residencial, sino también elementos del equipamiento urbano (los cuales suelen retroalimentar las diferencias). Así, el simbolismo asociado a "la zona" brinda un tipo de prestigio a los lugares que contiene, mismo que es reforzado por el imaginario sobre el tipo de gente que allí reside. Un ejemplo interesante de esta percepción es la forma en que algunos informantes explican las diferencias en la escala y calidad del desarrollo comercial en zonas económicamente contrastantes. Por ejemplo, en las percepciones de los empleados de una plaza comercial de Iztapalapa (Plaza del Salado) está presente esta zonificación urbana por tipos de oferta de consumo. Ellos se refieren reiteradamente al nulo prestigio de la zona como elemento definitorio tanto de la escala de la plaza, como de la calidad y reputación. No sólo la pobreza y la marginación, sino también la inseguridad y la violencia asociadas a esta parte de la ciudad se perciben como causas básicas para que los inversionistas de gran escala decidan no establecer allí sus empresas comerciales. ${ }^{7}$ Una

\footnotetext{
7 Esos efectos de la zona involucran también la propia definición de este centro
} 
empleada de otro centro comercial en la zona centro (Parque Delta) explica también que la diferencia de prestigio entre dos centros comerciales se define por su ubicación en zonas económicamente diferenciadas, así como por el tipo de personas que acuden a ellos.

Sí, éste [centro comercial] lo frecuentan muchos artistas. En Tezontle [Iztapalapa] no, eh... Es por la zona, aquí es como un Perisur pequeño... Pues es que está cerca el World [WTC] ¿no?, y entonces la mayoría viene para acá, y tú sabes que atrás del World es zona como más de dinero [María, 23 años, empleada de Parque Delta, habitante de Iztapalapa].

El prestigio de las "zonas" suele definirse entonces a partir de referencias simbólicas de la estratificación social que se basan en el estilo de vida de sus residentes, el equipamiento urbano, el desarrollo de espacios comerciales, así como el tipo de personas que los frecuentan. Dichos elementos se asocian de forma interdependiente y constituyen una imagen de la ciudad fragmentada con espacios de lógicas desiguales y diferentes.

En este estudio se desea destacar que residir no es lo mismo que habitar. Con el término de residencia se apela a una práctica estática, mientras que el habitar la ciudad, en un sentido amplio, involucra la movilidad y el desplazamiento. Así, la ciudad puede ser habitada a partir de los usos de sus espacios y lugares, ofreciendo múltiples experiencias subjetivas. El espacio citadino puede ser visto así como un espacio complejamente habitado, y más aún los intersticios de carácter netamente urbano, los espacios públicos. Aquí se adopta la noción de espacio urbano en el sentido de que lo urbano "no es tanto la ciudad en sí, como sus espacios usados transitoriamente" (Delgado, 1999: 33). Así, un espacio urbano suele ser usado y habitado intermitentemente por residentes de diferentes lugares, y de diversas adscripciones sociales, étnicas, culturales, etcétera.

Sin embargo, lo anterior no niega algunos efectos propiciados por la división social del espacio, pues el propio espacio público puede verse territorializado cuando se lo apropia un grupo social, especialmente cuando se encuentra en un territorio bien definido (como las

comercial para sus protagonistas. Tanto los empleados como algunos usuarios de esta plaza la conciben como un espacio de estricto consumo, un lugar donde "vas, compras y te vas". Al no poseer prestigio, ni brindar esparcimiento y diversión, elementos que consideran definitorios e inherentes de un "centro comercial", la Plaza del Salado, en Iztapalapa, no se puede considerar como tal, a diferencia de otros centros comerciales de mayor escala como Centro Santa Fe. 
calles de los barrios populares y las cerradas de las zonas residenciales), o bien cuando previamente se les diseña con fines más o menos elitistas y privativos (discotecas, clubes nocturnos o algunos centros comerciales), es decir, como espacios semipúblicos. Parece observarse así un orden de diferenciación social complejo cuando miramos el problema desde la relación público-privado. Es precisamente en esta dimensión en la que inscribimos algunas percepciones de nuestros informantes en relación con experiencias subjetivas de la estratificación y la desigualdad.

En los testimonios de experiencias en diversos espacios de la ciudad encontramos una conexión importante con prácticas de exclusión social. Si bien hemos ya comentado que el habitar la ciudad comprende la práctica del desplazamiento, éste sin embargo no suele ser automático sino selectivo. El uso y el traslado en la ciudad no están determinados completamente por una racionalidad utilitaria de cálculos de relación tiempo-espacio, pues el simbolismo asociado a sus espacios contribuye potencialmente. Un habitante de la ciudad construye su percepción de la misma en torno a sus experiencias, cuya configuración está estructurada por su hábitus (Bourdieu, 1995), es decir, el conjunto de disposiciones delineadas por las condiciones materiales, los gustos, los temores, los significados, etc. Estos hábitus contribuyen a generar intersubjetivamente categorías de lo que en palabras de Bauman constituyen espacios vacíos (2004), es decir, vacíos de sentido en la medida en que están prohibidos por barreras generalmente simbólicas que delimitan lógicas distintas y que se desconocen mutuamente (Saraví, 2008). Así, por ejemplo, los sectores altos y los bajos suelen trasladarse por la ciudad para desarrollar sus actividades laborales y de esparcimiento haciendo uso, sin embargo, de espacios y medios diferentes.

Con relación a lo anterior podemos identificar algunos espacios que contribuyen a reforzar la división social de las áreas urbanas de manera explícita, como las calles privatizadas y las zonas residenciales fortificadas. Por otro lado, también existen espacios semipúblicos que, con base en criterios que aluden a la identificación de la clase y el estatus social, se reservan el derecho de admisión de los asistentes. Es con relación a este derecho o restricción de acceso a un lugar que se genera una experiencia representativa de la vida urbana. El ejemplo más claro para nuestros informantes lo constituye la "selectividad" del público a la entrada de las discotecas o centros nocturnos juveniles, mejor conocidos como "antros". 
Pues así, yo que voy así a clubs... ah, bueno a antros y eso, pues luego los que están en la puerta dicen, o sea si no te ven así, bien vestido, este, no te dejan pasar y así... o en algunos lugares si no traes zapatos no te dejan pasar. Pues así, es como una forma de discriminar, que dices "pues qué" ¿no? [Edgar, 18 años, Campestre Coyoacán, estudiante de bachillerato].

No, casi no voy. Mi primo sí iba muy seguido, pero a la Zona Rosa, supuestamente que con tenis no te dejan entrar, con puros zapatos... entonces yo siento que sí discriminan mucho a las personas muy feo [Cintia, 20 años, Chicoloapan, Estado de México, estudiante de licenciatura].

Los antros ¿no?, es así como el típico ejemplo. Llegas a la cadena y si los cadeneros ven que está fea la persona, o que está mal vestida la persona, no la dejan pasar. Se supone que eso ya no se puede, pero yo he visto que sí lo hacen [Fanny, 21 años, Santa Fe, Cuajimalpa, estudiante de licenciatura].

Aunque se observa una diferencia por sectores sociales entre asistir o no asistir a este tipo de "antros", lo cierto es que el conocimiento de la práctica selectiva de los clientes en la puerta de esos lugares está ampliamente difundido. Ello propicia que el personaje conocido como "cadenero" sea objeto de críticas reiteradas por sus actitudes discriminatorias; sin embargo su actuación también es un elemento clave de la "exclusividad" de dichos lugares. Algunos estudios aseguran que dicha práctica de exclusión y discriminación proporciona prestigio a estos lugares, pues en la medida en que es restringida la entrada a cierto tipo de personas se ofrece implícitamente un ambiente de exclusividad como estrategia publicitaria (Urteaga y Ortega, 2004). Este aspecto es interesante, pues muestra cómo la lógica del prestigio opera mediante un juego de exclusividad-exclusión en algunos espacios. Por otro lado, muestra que dicha relación suele establecerse en las interacciones implicadas en contextos comerciales o de servicio. Las prácticas selectivas, como el "derecho reservado de admisión", se asocian principalmente a lugares donde hay una relación de oferta-demanda de productos o servicios dirigidos a la gente "bien". No obstante, aunque los casos más representativos son los clubes nocturnos, discotecas o "antros", una práctica sutil de este tipo también suele asociarse a otros lugares semipúblicos en progresiva expansión, como los centros comerciales:

Fíjate que una vez me tocó en Liverpool, fui a ver un anuncio, y me tocó ver a un señor que se veía que trabajaba de mecánico, y ves que se ensu- 
cian... y no tuvo la precaución a lo mejor de cambiarse o de asearse. Entonces no lo dejaron entrar, que por la imagen de la tienda no podía entrar el señor. El argumento es que iba a comprar, que tenía dinero para comprar. Y le dijeron que no, por la imagen simplemente [Javier, 30 años, Cuajimalpa, empleado de Centro Santa Fe].

Observamos así una conexión de las experiencias de la desigualdad con diferentes espacios que albergan relaciones, o mejor dicho interacciones, de servicio comercial. Los centros comerciales, a pesar del anterior testimonio, no suelen ser lugares que se caractericen por ejercer explícitamente la práctica de seleccionar a sus visitantes (pues mantienen la apariencia de ser un espacio de libre acceso), sino que normalmente lo logran de una manera sutil. Un factor disuasivo es por ejemplo el conjunto de elementos que incluyen la ubicación en una zona específica, el tipo de tiendas que contiene, y en general la reputación de exclusividad que se forma en torno a ella. Otra de esas formas sutiles está asociada con las experiencias de trato discriminatorio en las interacciones de servicio, incluso con los otros usuarios.

Yo tengo una experiencia personal. Entré a una tienda, o sea, yo estaba en Europa, y andaba en pants, todo mal y así, y entró también una señora que se veía con su bolsa y así. Luego luego, o sea, a mí me tomaron como "este niño nada más viene a ver". Y pues a la señora la atendían, o sea, estaban atrás de la señora. [Ella] se estaba probando muchos zapatos y así. Y ahí sí fue cuando dije "no vuelvo a entrar asî". Como me veía, o sea en pants, chico y entré sólo, han de haber dicho, "este niño seguro no va a comprar nada”. [Entrevistador: ¿Y aquí en México, digamos?] No eh, aquí en México..., así que me haya sentido discriminado, no [Juan, 22 años, Santa Fe, Cuajimalpa, estudiante de licenciatura].

He ido con mis compañeras [a Perisur]... y no nos sentimos a gusto, mejor nos vamos [...] Nos sentimos así, como que sentimos que la gente se nos queda viendo. Hasta cuando fuimos a comprar un helado, que fuimos una vez a comprar a Perisur un helado y como que no, y "espéreme tantito". Oye, dame un helado... "espéreme tantito, ellos llegaron primero". Ay no, vámonos. Y que nos salimos. O sea, luego luego sentimos eso, y ya nos salimos... Yo creo por la clase social ¿no? Están más preparados por allá, la gente se viste mejor que nosotros, luego luego se les ve en las ropas y nosotros vamos así con chanclas. Pues la gente de allá está más... están sus zapatos boleados... nosotras todas greñudas. No nos gusta ir [Lupe, 50 años, Santa Marta, Iztapalapa, empleada de limpieza]. 
De tal suerte que con estos testimonios se reitera un conjunto de prácticas que suelen contribuir al establecimiento de barreras simbólicas en torno a ciertos espacios. Llama la atención que este tipo de experiencias nuevamente suelen tener matices perceptivos influenciados por las trayectorias biográficas y las posiciones sociales de las personas, pues sus experiencias de discriminación se basan en referentes socioeconómicos diferentes. En los testimonios que recopilamos sobre las experiencias respecto a lugares como los centros comerciales encontramos referencias reiteradas a un elemento: la conducta visual. Algunas prácticas que involucran dicha conducta son por ejemplo, los gestos de descalificación, la vigilancia y el escrutinio hacia el "otro". Este aspecto llama nuestra atención en la medida en que aparece como uno de los marcos de referencia más representativos de la experiencia socioespacial urbana.

\section{"Como te ven te tratan"}

Para Walter Ong (1987) las sociedades con fuerte tradición oral encuentran en los refranes populares, adagios o proverbios, fórmulas que ayudan a aplicar un discurso rítmico y que sirven como recurso mnemotécnico por derecho propio. Estas fórmulas constituyen así la sustancia del pensamiento mismo. En nuestra sociedad, a pesar de que existe desde hace mucho tiempo un impulso por la tradición escrita, la tradición oral sigue siendo muy importante y parece seguir siendo la vía más usual mediante la cual se reproduce el sentido común en amplios sectores de nuestra sociedad.

Una de las cualidades del sentido común, sostenía Clifford Geertz, es su practicidad, en la medida en que no se emplea tanto en el sentido pragmático de lo útil, sino en un sentido amplio, filosófico popular, de "astucia" sobre el conocimiento (1994). La frase popular "como te ven te tratan" hace referencia a un adagio de sentido común que representa situaciones cotidianas en las que se pone de manifiesto una actuación conforme a valores sociales y morales. Esta frase puede referirse a diversos ámbitos, sin embargo en los testimonios que registramos se adapta perfectamente como marco de significación para situaciones de diferenciación social relativas a determinadas experiencias en el espacio urbano.

La práctica a la que se hace referencia se fundamenta en el carácter visual de ciertos elementos estrictamente sociales que se depositan 
en el cuerpo. Dichos elementos se reconocen por ejemplo en el tipo de ropa, la forma de vestir y el arreglo personal en general, y esto determina una parte importante de lo que se desarrolla en un encuentro social. Así, al evaluar en los "otros" la calidad y el estado del calzado, de la ropa y de los accesorios personales que fungen como símbolos de estatus, se busca información acerca de su identidad social (Goffman, 2003). Otra parte del ámbito perceptivo que se exalta en el adagio tiene que ver con el comportamiento o el "porte". Respecto a éste se observan principalmente el lenguaje corporal, los gestos y las posturas que se adoptan, así como la forma de hablar. Mediante ello se suele inferir el nivel de estudios, el ámbito laboral y social en el que se desenvuelve cotidianamente el otro presente, e incluso el tipo de lugar donde reside.

Podemos decir que en general las percepciones que evocan la frase "como te ven te tratan" definen la práctica de la mirada tanto en un modo perceptivo como en un sentido gestual. Por ejemplo, un trato negativo se refiere a hacer un gesto de desprecio, como indican las frases populares "ver feo", "ver con malos ojos" o "hacerle el feo" a alguien. En el sentido positivo los informantes resaltan la cordialidad y, cuando se trata de una relación mercantil o de servicio, la atención servil. De tal suerte, no sólo es el modo de percibir un proceso subjetivo, sino junto con ello la forma de dirigir la mirada y convertirla en expresión, en un acto enunciativo.

Como mencionamos anteriormente, una parte importante de este tipo de sucesos se vincula estrechamente con las prácticas de vigilancia de ciertos espacios, y entre ellos el centro comercial es ejemplar. Tomemos por caso la sensación de vigilancia especial de la que podrían ser objeto ciertas personas que, según infieren los testimonios, es consecuencia de su "aspecto":

Mire, si usted va a Liverpool lo dejan entrar y pasa fácil y va, y anda pa'rriba y pa'bajo. Sanborns... va y anda pa'rriba y pa'abajo y agarra las revistas, pero siempre está vigilado. Yo pienso que sí debería haber vigilancia. Pero cuando lo ven a uno un poquito que no va bien arreglado, que va uno de..., de mezclilla así... como que cuidan más a la persona que va así. Aunque sea una persona honrada. En cambio el que va para allá más arreglado, no es la misma vigilancia que le tienen; eso se nota en todas las tiendas [Pedro, 73 años, Santa Marta, Iztapalapa, obrero jubilado].

Aunque la práctica de la vigilancia es parte explícita de los controles sociales que en ciertos lugares se ejercen, en especial en los semi- 
públicos, es interesante la conexión con los imaginarios de la delincuencia, sus tintes clasistas y todo lo que ello abarca. ${ }^{8}$

La experiencia de sentirse observado y juzgado remite a un tipo de situaciones que alimentan sin duda parte del proceso de socialización de los protocolos de poder. El hecho de estar en un lugar con el que se está poco familiarizado, que se percibe como elitista o de un estrato socioeconómico superior -por ejemplo algunos restaurantes de lujo o centros comerciales exclusivos, como describieron algunos informantes de estratos populares- puede provocar una sensación de vulnerabilidad en quien se siente observado y juzgado. Específicamente en palabras de los informantes es "una sensación de vergüenza o incomodidad", que podemos interpretar como una forma de experimentar un "espacio vacío” (Bauman, 2004). En la opinión de Gabriela Vergara (2008) esa sensación de vulnerabilidad adquiere una especial significación en la medida en que pone de manifiesto un contexto de configuraciones sociales basadas en relaciones desiguales. ${ }^{9}$ Norbert Elías refiere, por ejemplo, que en el proceso de civilización occidental en la Edad Media de los países centroeuropeos, la vergüenza, así como el orgullo, por su estructura emotiva forman parte del cambio psicosocial de control de los seres humanos, y que en adelante distinguirán a una clase social de otra (Elías, 1987). Podemos decir que parte de esta estructura emotiva está tan presente en nuestra sociedad que suele expresarse en situaciones cotidianas en que ocurren contactos entre diferentes.

Como ya expusimos, en las valoraciones en torno a los espacios de la ciudad suelen corresponder la infraestructura urbana y las valoraciones sobre las personas a las que se vinculan. En esta forma los procesos inmersos en las experiencias espaciales de la ciudad son de alguna manera experiencias relacionadas con sus tipos de "habitantes". Así, las identidades sociales emergen como un factor importante en el complejo proceso de experiencia de la ciudad, desde la perspectiva de la desigualdad social. En este sentido, la definición de la situación de interacción implica la puesta en juego de la identidad personal, la cual

${ }^{8}$ Este tipo de prácticas son reproducidas no sólo en estos ámbitos, sino también en escenarios de índole internacional de supuesta seguridad nacional. Por ejemplo, el controvertido caso de la ley antiinmigrante (SB 1070) puesta en vigor en el estado fronterizo de Arizona, en Estados Unidos, la cual ha sido calificada por sus críticos como racista porque reconoce el derecho de los policías a detener e interrogar a cualquier persona bajo sospecha de permanencia ilegal en el país, lo que necesariamente se funda en la apariencia física.

${ }^{9}$ En dicho artículo la autora realiza una revisión sobre la dimensión sociológica de la vergüenza en las obras de tres grandes teóricos: Simmel, Giddens y Elías. 
depende de la disponibilidad de marcos interpretativos como los que se han explorado anteriormente.

En un apartado previo hicimos alusión a la importancia de la presentación de la persona, con relación a la tendencia general de autocategorización en la clase media dentro de la escala de estratificación social. Distinguimos entre una percepción "natural" o ingenua y una actitud intencional. Ahora ponemos énfasis en la segunda, pues sostenemos que forma parte de los argumentos centrales en las interacciones sociales de desconocidos. Nos preguntábamos ¿cómo es que una persona decide, más allá de la percepción real de sí misma, presentarse de cierta forma? Para este propósito consideramos útil la propuesta de Brownin Davies y Rom Harré (1990) respecto al concepto de "posicionamiento de la identidad", para hablar de la producción discursiva inmersa en una diversidad de identidades que emergen en las interacciones conversacionales. El posicionamiento implica un proceso envuelto en términos de categorías y argumentos:

es el proceso discursivo donde las identidades se localizan en conversaciones en las que participantes, observable y subjetivamente coherentes, conjuntamente producen argumentos. Puede haber posicionamiento interactivo cuando lo dicho por una persona posiciona a otra. Y puede haber posicionamiento reflexivo cuando uno se posiciona a sí mismo [Davies y Harré, 1990].

El aspecto que se ha destacado en los ejemplos previos corresponde a un posicionamiento reflexivo. Poner el acento en este proceso sirve para dirigir nuestra atención a un proceso por medio del cual ciertas series de consecuencias son puestas en movimiento. Nuestro posicionamiento nos hace traer una historia subjetiva con sus emociones y creencias concomitantes, así como también un conocimiento de estructuras sociales (incluyendo los roles) con sus derechos, obligaciones y expectativas inherentes (Davies y Harré, 1990). De tal suerte, el acto de posicionamiento discursivo como miembro de la clase media frente a un desconocido puede ser entendido como una toma de postura que involucra categorías y argumentos consistentes con una estructura moral vinculada a la estratificación social. En otras palabras, emerger discursivamente como una persona de clase media permite al sujeto adoptar una posición neutra desde la cual partir al encuentro con desconocidos.

Por supuesto, las situaciones de interacción social en los espacios urbanos implican no sólo los encuentros entre diferentes, sino también 
los desencuentros, ambos inmersos en un contexto de conflicto desencadenado por la desigualdad social (Saraví, 2008). En tal caso la situación puede tomar giros inesperados y se contiende por defender la posición identitaria menos vulnerable.

\section{A manera de conclusión}

Como hemos visto a lo largo del texto, mediante la exploración de las experiencias de los habitantes de la ciudad al transitar por ésta, se advierten vínculos significativos entre los ámbitos espacial, emotivo e identitario. Son ejemplos de ello los tópicos anteriormente analizados. Para ello fue necesario indagar empíricamente en aquellos elementos socioculturales que los sujetos aprehenden mediante la experiencia y que funcionan como marcos de referencia para establecer definiciones de la situación. Sin embargo, dado que el problema de investigación se orientó especialmente hacia las estructuras de desigualdad social, la exploración de dichos marcos de referencia se centró en la experiencia sobre las mismas. Así, el análisis exploró la relación entre la experiencia del espacio urbano y los procesos de desigualdad, estratificación y diferenciación social, como un ejercicio de contribución a su reflexión fenomenológica.

En primer lugar, hay que subrayar la valoración en términos de prestigio o estigma de las diferentes áreas de la ciudad, la dimensión territorial en cuanto a sus usos o a la división social del espacio, y el juego sutil de exclusividad y exclusión en ciertos círculos y espacios sociales. Éstos develan un panorama interesante con relación al problema de la cohesión social y ponen de relieve una eficacia simbólica de la fragmentación social en la Ciudad de México. De esta manera observamos que la experiencia socioespacial en la ciudad contribuye a conformar mapas en los que parte importante de la significatividad de los espacios se define a partir de sus diferencias en la dimensión de la desigualdad social. Así, ciertos espacios están definidos por estigmas territoriales asociados a la pobreza y la inseguridad, mientras que otros se definen por su prestigio, y en ellos se insertan otros espacios locales que explotan las cualidades de exclusividad y exclusión. Existen así, en las geografías subjetivas, espacios significativos y espacios vacíos de significado que son diferentes para cada sector social, los cuales están dados en función de la familiaridad y la apropiación de los mismos. 
Por otro lado, tanto la existencia de percepciones diferenciadas de la estratificación desde distintos estratos, así como la tendencia a percibirse dentro de un nivel socioeconómico medio, aun la de quienes oficialmente no se situarían ahí, son también efectos fenomenológicos de la fragmentación y el aislamiento social propiciados por la segregación espacial o la división social del espacio.

En el texto distinguimos entre la autopercepción y la presentación de sí mismo en un estrato social medio. Con relación a la segunda sostuvimos que se trata de una forma de posicionarse en una zona neutra desde la cual es posible evadir el latente distanciamiento de clase. No obstante, dicha decisión tiene además un componente subjetivo arraigado en las estructuras de poder y desigualdad de las sociedades occidentales. De esta manera las estructuras emotivas, del orgullo y la vergüenza, fomentadas por las estructuras de desigualdad y que distinguen a una clase de otra, forman parte del ámbito fenomenológico de la experiencia urbana en la Ciudad de México.

Lo anterior subraya características importantes en la relación que los habitantes mantienen con la ciudad y con el espacio urbano. Éstas pueden resultar fundamentales para plantear reflexiones en torno a la cuestión de cómo se construye el orden social en las interacciones sociales que se desarrollan en los espacios urbanos y, consecuentemente, cómo éstas sostienen o desafían las estructuras sociales del contexto en que están insertas.

\section{Bibliografía}

Bauman, Zygmunt (2004), Modernidad líquida, Buenos Aires, FCE.

Berger, Peter. L. y Thomas Luckman (1988) [1968], La construcción social de la realidad, Buenos Aires, Amorrortu.

Bourdieu, Pierre (1995), "Habitus, illusio y racionalidad", en Pierre Bourdieu y Loïc D. Wacquant, Respuestas, por una antropología reflexiva, México, Grijalbo, pp. 79-99.

Caldeira, Teresa (2007) [2000], Ciudad de muros, Barcelona, Gedisa.

Dalmau Torvà, Marc (2007), "Una mirada sobre la plaça ordinària”, tesina de posgrado, Barcelona, Departamento de Antropología Cultural e Historia de América y África, Universidad de Barcelona.

Davies, Bronwyn y Rom Harré (1990), "Positioning: The Discursive Production of Selves", Journal for the Theory of Social Behaviour, vol. 20, núm. 1, pp. 43-63. 
Delgado, Manuel (1999), El animal público. Hacia una antropología de los espacios urbanos, Barcelona, Anagrama.

Duhau, Emilio (2003), "División social del espacio metropolitano y movilidad residencial”, Papeles de Población, núm. 36, pp.161-210.

Elías, Norbert (1987) [1934], El proceso de la civilización, Madrid, FCE.

Flick, Uwe (2004), Introducción a la investigación cualitativa, Madrid, Morata.

Geertz, Clifford (1994), Conocimiento local: ensayos sobre la interpretación de las culturas, Barcelona, Paidós.

Goffman, Erving (2003) [1963], Estigma. La identidad deteriorada, Buenos Aires, Amorrortu.

Goffman, Erving (2006) [1974], Frame Analysis. Los marcos de la experiencia, Madrid, Siglo XXI.

Hernández Espinosa, Rafael (2009), "Una aproximación a la dimensión fenomenológica de la exclusión social: la Zona Metropolitana de la Ciudad de México", en Sebastián Goinheix (coord.), Conflictos y expresiones de la desigualdad y la exclusión en América Latina, Buenos Aires, El Aleph.

Joseph, Isaac (1999), Retomar la ciudad. El espacio público como lugar de acción, Medellín, Universidad Nacional de Colombia.

López Levi, Liliana (1999), Centros comerciales. Espacios que navegan entre la realidad y la ficción, México, Nuestro Tiempo.

López Romo, Heriberto (2008), Nivel socioeconómico AMAI, México, Asociación Mexicana de Agencias de Investigación de Mercado y Opinión Pública.

Machado Barbosa, Eva (2001), "Urban Spatial Segregation and Social Differentiation: Foundation for a Typological Analysis", ponencia presentada en el International Seminar on Segregation in the City, Cambridge, Lincoln Institute of Land Policy, 26 al 28 de julio.

Ong, Walter J. (1987) [1982], Oralidad y escritura. Tecnologías de la palabra, México, Fondo de Cultura Económica.

Portes, Alejandro (1999), "Capital social: sus orígenes y aplicaciones en la sociología moderna”, en Jorge Carpio e Irene Novacovsky (coords.), De igual a igual: el desafío del Estado ante los nuevos problemas sociales, Buenos Aires, FCE / Siempro / Flacso, pp. 243-266.

Portes, Alejandro y Bryan Roberts (2004), "Empleo y desigualdad urbanos bajo el libre mercado. Consecuencias del experimento neoliberal”, Nueva Sociedad, núm. 193, pp. 76-96.

Sacks, Harvey (2000) [1992], "La máquina de hacer inferencias”, en Félix Díaz (comp.), Sociologías de la situación, Madrid, La Piqueta, pp. 61-81.

Saraví, Gonzalo (2004), "Segregación urbana y espacio público", Revista de la CEPAL, núm. 83, pp. 33-84.

Saraví, Gonzalo (2004a), "Mundos separados: percepciones y experiencias de la segregación urbana en jóvenes de sectores populares”, comunicación presentada en el Foro Internacional sobre Juventud: "Juventud ¿divino tesoro?", Ciudad de México, 18 de agosto. 
Saraví, Gonzalo (2008), "Mundos aislados: segregación urbana y desigualdad en la Ciudad de México”, Eure, vol. 34, núm. 103, pp. 93-110.

Schteingart, Martha (2008), "Ciudades divididas: segregación y pobreza en la Ciudad de México”, ponencia presentada en el LII Congreso Mundial de Planificación y Vivienda, San Juan de Puerto Rico, 12 al 15 de octubre. Disponible en: <www.coljal.edu.mx/congreso/MarthaSchteingart.pdf> (17 de diciembre de 2011).

Schütz, Alfred (1993) [1932], La construcción significativa del mundo social. Introducción a la sociología comprensiva, Barcelona, Paidós.

Schütz, Alfred (2003) [1962], El problema de la realidad social. Escritos I, Madrid, Amorrortu.

Somoza Medina, José (1995), "La geografía de la percepción como instrumento de ayuda al planeamiento urbano. Un posible ejemplo en la ciudad de Ourense", ponencia presentada en las II Jornadas de Geografía Urbana, Alicante, Universidad de Alicante.

Sznol, Florinda Eleonora (2007), "Geografía de la resistencia. Protesta social, formas de apropiación y transformación del espacio urbano en la Argentina (1996-2006)", Theomai, núm. 15, pp. 21-34.

Taylor, Steven J. y Robert Bogdan (1994), Introducción a los métodos cualitativos de investigación. La búsqueda de significados, Barcelona, Paidós.

Urteaga, Maritza y Enedina Ortega (2004), "Identidades en disputa: fresas, wannabes, pandros, alternos y nacos", en Rossana Reguillo et al. (coords.), Tiempo de híbridos. Entre siglos. Jóvenes México-Cataluña, México, SEP / IMJ / IIMU.

Vergara, Gabriela (2008), "Conflicto y emociones. Un retrato de la vergüenza en Simmel, Elías y Giddens como excusa para interpretar prácticas en contextos de expulsión”, en Adrián Escribano y Carlos Figari (comps.), Cuerpos, subjetividades y conflictos. Hacia una sociología de los cuerpos y las emociones en Latinoamérica, Buenos Aires, Clacso / Ciccus.

Wacquant, Loïc J.D. (1995), “Introducción”, en Pierre Bourdieu y Loïc D. Wacquant, Respuestas. Por una antropología reflexiva, México, Grijalbo, pp. 15-38.

Weber, Max (1974) [1922], "Clase, estamento y partido", en Claudio Stern (comp.), La desigualdad social II. Teorías de la estratificación y la movilidad sociales, México, Sepsetentas, pp. 7-29. 


\section{Acerca del autor}

Rafael Hernández Espinosa es doctor en Antropología Social (CIESASDF) con estudios de licenciatura en Psicología Social (UAM-I). Su tesis de maestría “'Aquí nadie te hace el feo...'. Aproximaciones a la dimensión fenomenológica de la exclusión social” obtuvo mención honorífica en el IV Concurso Nacional de Tesis sobre Juventud (2007). Realizó una estancia doctoral en el Departamento de Antropología y de Historia de América y África de la Universidad de Barcelona (2010). Actualmente es profesor titular de tiempo parcial en el Departamento de Sociología de la UAM Iztapalapa. Sus intereses se perfilan hacia los métodos de investigación cualitativa, la imagen y la dimensión visual de la vida social, la construcción del espacio, el espacio público y la desigualdad social. Entre sus más recientes trabajos están "El espacio urbano y el trabajo de lo social sobre sí mismo. Entrevista con Manuel Delgado Ruiz” (2013), publicado en Sociológica, núm. 80, pp. 281-290, y "Una aproximación a la dimensión fenomenológica de la exclusión social: la Zona Metropolitana de la Ciudad de México” (2009), publicado en Sebastián Goinheix (coord.), Conflictos y expresiones de la desigualdad y la exclusión en América Latina, Buenos Aires, Elaeph, pp. 39-78. 